\title{
Evaluation of the Value of Contrast-Enhanced Ultrasound (CEUS) within Radiology Departments in Germany
}

\author{
Erhebung der Wertigkeit der kontrastverstärkten \\ Sonografie (CEUS) in radiologischen Fachabteilungen \\ in Deutschland
}

Authors

Tilmann Graeter ${ }^{1}$, Wolfgang Kratzer², Thomas Seufferlein², Suemeyra Tasdemir ${ }^{2}$, Aylin Senguel², Julian Schmidberger², Hartmut Graeter ${ }^{3}$, Christian Stroszczynski ${ }^{4}$, Meinrad Beer ${ }^{1}$

Affiliations

1 Department of Diagnostic and Interventional Radiology, University Hospital Ulm, Germany

2 Department of Internal Medicine I, University Hospital Ulm, Germany

3 Department of Internal Medicine, Oncology, Hematology, Gastroenterology, Esslingen Hospital, Esslingen, Germany

4 Department of Radiology, University Hospital Regensburg, Germany

Key words

CEUS, questionnaire study, radiology, contrast-enhanced ultrasound

received 15.12.2016

accepted 12.04.2017

Bibliography

DOI https://doi.org/10.1055/s-0043-111011

Published online: 26.6.2017 | Fortschr Röntgenstr 2017; 189:

748-759 @ Georg Thieme Verlag KG, Stuttgart · New York, ISSN 1438-9029

Correspondence

Dr. Tilmann Graeter

Department of Diagnostic and Interventional Radiology, University Hospital Ulm, Albert-Einstein-Allee 23, 89081 Ulm, Germany

Tel.: +49/7 31/50061175

tilmann.graeter@uniklinik-ulm.de

\section{ABSTRACT}

Purpose Contrast-enhanced ultrasound (CEUS) has been established for many years and has become an increasingly important cornerstone of the diagnostic imaging of various organ systems. However, this modality is rarely performed by radiologists and is primarily employed by other medical disciplines. The goal of this questionnaire study is to present the current value of CEUS in radiology and to encourage reevaluation of the method within this medical discipline.

Materials and Methods 560 directors of radiology departments throughout Germany were contacted and given a 3-page questionnaire. The questionnaire included 37 questions on 5 different topics (general structures, CEUS and interdisciplinarity, CEUS in pediatric radiology, education/professional development, outlook) to assess the value of ultrasound (US) and in particular CEUS in radiology.

Results The response rate was $42.3 \%$. A statistical analysis of the answers was performed, including subgroup analysis. Overall, it could be shown that CEUS is performed in comparatively few radiology departments (26.6\%), while the current value of the modality is given an average to high range of importance even by radiologists. More than half of all participating radiologists $(54.9 \%$ ) would like this method to be included in the requirements catalog for the specialist examination.

Conclusion The nationwide questionnaire to evaluate CEUS within radiology departments in Germany had a very high response rate, which reflects the assessment of this topic by radiologists. There is a substantial discrepancy between the currently low utilization of CEUS in radiology and the high ranking of CEUS by many radiologists. The analyses of the replies point out important aspects of professional policy regarding this topic within the radiology community.

\section{Key points}

- The high response rate reflects the assessment of this topic by radiologists.

- The questionnaire study depicts the currently low use of CEUS in radiology.

- CEUS is given a high range of importance by radiologists.

\section{Citation Format}

- Graeter T, Kratzer W, Seufferlein T et al. Evaluation of the Value of Contrast-Enhanced Ultrasound (CEUS) within Radiology Departments in Germany. Fortschr Röntgenstr 2017; 189: 748-759

\section{ZUSAMMENFASSUNG}

Ziel Kontrastverstärkter Ultraschall (CEUS) ist seit Jahren methodisch etabliert und eine zunehmend wichtige Säule der Bildgebung unterschiedlicher Organsysteme. Allerdings wird die Modalität nur selten von Radiologen, sondern meist 
innerhalb anderer Fachdisziplinen praktiziert. Die vorliegende Fragebogenstudie soll den aktuellen Stellenwert von CEUS in der Radiologie darstellen und zu einer Reevaluation der Verankerung dieser Methode innerhalb des Fachgebiets anregen.

Material und Methoden Es wurden 560 ärztliche Leiter radiologischer Abteilungen in ganz Deutschland angeschrieben und ein 3-seitiger Fragebogen vorgelegt. Anhand von 37 Fragen zu 5 Themenkomplexen (Allgemeine Strukturen, CEUS und Interdisziplinarität, CEUS in der Kinderradiologie, Ausbildung/Fortbildung, Ausblick) wurde der Stellenwert von Ultraschall (US) und insbesondere von CEUS in der Radiologie erfragt.

Ergebnisse Die Rücklaufquote betrug 42,3\%. Es erfolgte eine statistische Auswertung der Antworten, einschließlich Subgruppenanalysen. Insgesamt zeigte sich, dass CEUS zwar in vergleichsweise wenigen radiologischen Abteilungen prak- tiziert wird (26,6\%), aber der Stellenwert der Methode auch von Radiologen meist im mittleren bis hohen Bereich gesehen wird. Sogar über die Hälfte (54,9\%) würde eine Verankerung der Methode in der radiologischen Facharztweiterbildung begrüßen.

Schlussfolgerung Die hohe Rücklaufquote der bundesweiten Fragebogenstudie zur Erhebung der Wertigkeit von CEUS in der Radiologie spiegelt die Wahrnehmung der Wichtigkeit des Themenkomplexes durch die radiologische Fachdisziplin wieder. Es zeigte sich eine große Diskrepanz zwischen der aktuell geringen Anwendung der Methode innerhalb der Radiologie und der dennoch relativ hohen Einschätzung des Stellenwerts von CEUS durch viele Radiologen. Die Auswertungen der Fragestellungen eröffnen wichtige berufspolitische Aspekte dieser Thematik innerhalb der radiologischen Fachdisziplin.

\section{Introduction}

Contrast-enhanced ultrasound (CEUS) has been established for many years and has become an increasingly important cornerstone of imaging. CEUS is important not only for the evaluation of liver lesions [1 - 3] but also for the diagnosis of pathologies of other parenchymatous organs, for vascular diagnosis $[4,5]$ and for intracavitary purposes [6]. Due to its high diagnostic significance, CEUS should be increasingly used also for diagnosis in trauma cases in the future [7]. Analysis of the current situation indicates that this modality is only rarely used by radiologists and is primarily employed by other medical disciplines. However, use and evaluation of this important method in combination with $\mathrm{CT} / \mathrm{MRI}$ imaging would provide significant added value for radiologists in particular [8]. The integration of the method in the $\mathrm{S} 3$ guidelines for HCC with equivalence to $\mathrm{CT} / \mathrm{MRI}$ imaging shows that contrast-enhanced ultrasound has already reached a high level of diagnostic importance [9].

It can be expected that constant technical development and improvement of the method will further increase its value and expand its indications for use. The FDA recently approved CEUS for diagnostic liver imaging in children in the USA [10]. In the long term, insufficient use of this method in radiology would result in the diagnostic spectrum of the radiology discipline being incomplete $[8,11]$.

The goal of this questionnaire study is to present the current value of ultrasound (US) and specifically CEUS in radiology and to encourage reevaluation of the inclusion of this method in this medical discipline.

\section{Materials and Methods}

Initiated by the diagnostic and interventional radiology department at the University of UIm and the affiliated interdisciplinary central ultrasound unit and on behalf of the ultrasound working group of the German Radiological Society, 560 directors of radiol- ogy departments throughout Germany were contacted twice (letter 5/2015 and fax 6/2015) and were given a 3-page questionnaire to be completed anonymously. Respondents were allowed to specify the zip code of their department if desired.

The questionnaire included 37 questions regarding 5 topics (general structures, CEUS and interdisciplinarity, CEUS in pediatric radiology, education/professional development, outlook) to assess the value of US and in particular CEUS in radiology. The questions included 32 closed-ended questions, 4 open-ended questions, and 1 scaled question. The 32 closed-ended questions included 22 "single choice" questions and 9 "multiple response" questions.

In the second correspondence, the contacted departments were informed of the interim response rate and were again asked to participate if they hadn't already done so. Clinics with their own radiology department and radiology departments connected to clinics throughout Germany were identified based on the national hospital directory www.deutsches-krankenhausverzeichnis.de and the database www.kliniken.de and were contacted. The questionnaire could be returned per fax or mail.

Statistical analysis of the responses including subgroup analyses using the statistics program SAS 9.2 (SAS Institute Inc., Cary NC, USA) was performed. The ethics commission of the State Medical Chamber of Baden-Württemberg approved the study. The study was performed in accordance with the guidelines of the Helsinki Declaration and the GCP recommendations.

\section{Results}

The response rate was $33.4 \%$ (185 of 560) after the first letter and the final response rate was $42.3 \%$ (237 of 560) after the second letter.

The return rates were highest in the north (Schleswig-Holstein $90 \%$ ) and northeast (Mecklenburg-Vorpommern 60\%) followed by the middle of eastern Germany (Sachsen-Anhalt $47.8 \%$ ) and 


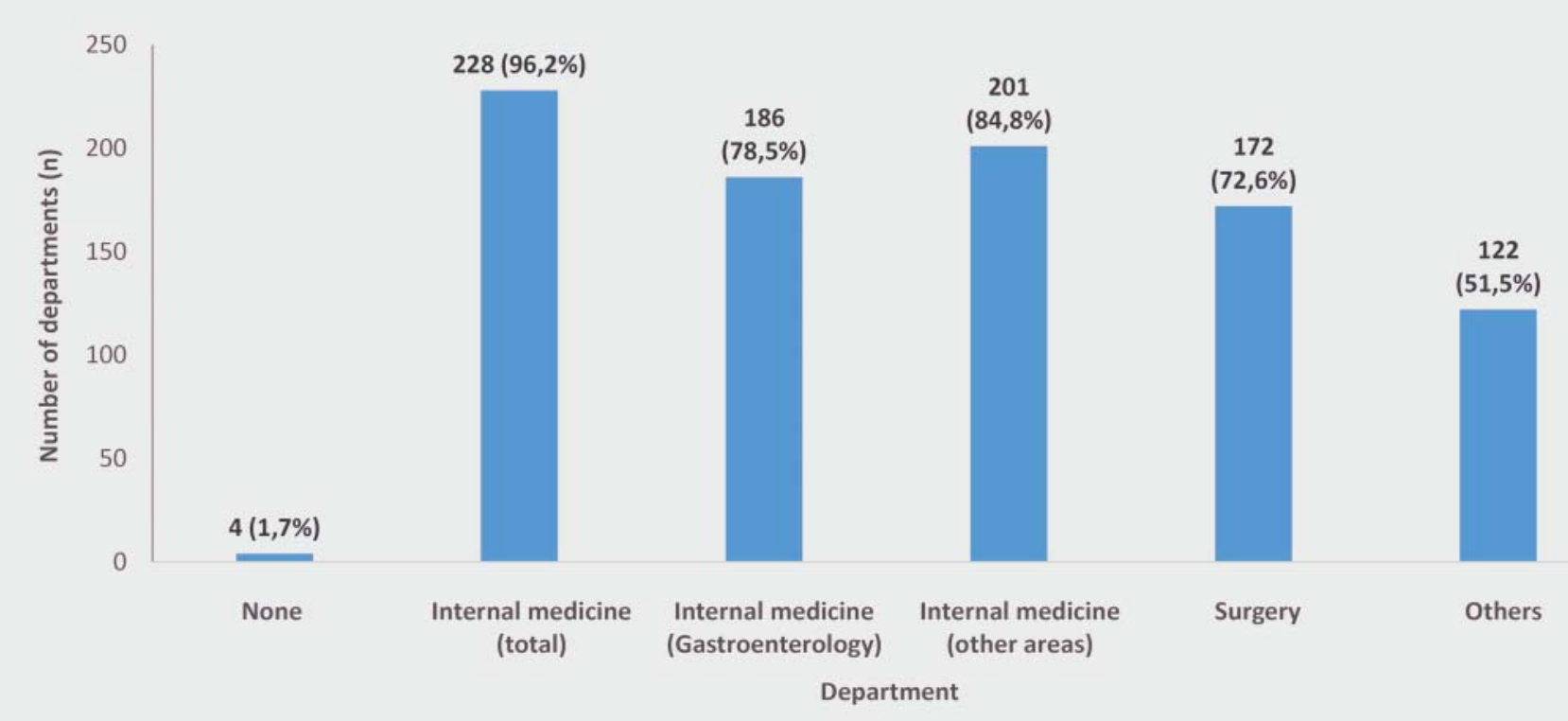

- Fig. 1 Medical disciplines apart from radiology performing abdominal and/or vascular ultrasound, in relation to all 237 participating clinics.

the south (Bavaria 42.6\%). The lowest return rates were in the middle states in western Germany, with Hessen having the lowest rate of $26.7 \%$.

\section{Analysis of the questionnaire according to topic}

\section{General structures}

$96.2 \%$ of responses came from clinics with their own radiology department and $3.8 \%$ from radiology departments affiliated with clinics. Both groups are referred to as (radiology) departments in the following. In total, most responses came from medium-sized clinics (<800 beds) with radiology departments $<1=20$ physicians and radiology equipment usually including $1-3$ CT and MRI units (approx. 2/3 without hybrid methods of crosssectional imaging).

In $81.4 \%(n=193)$ of cases, ultrasound examinations (routine and emergency diagnostic imaging combined) are performed in radiology departments. In total, $78.5 \%(n=186)$ of radiology departments perform ultrasound as part of routine diagnostic imaging.

However, ultrasound examinations are also performed by other disciplines, primarily internal medicine (96.2\%) with a focus in gastroenterology (78.5\%). Therefore, internal medicine (total), gastroenterology and "other" areas of specialization in internal medicine performing ultrasound either instead of or in addition to gastroenterology at the particular clinic were listed separately in the statistical analysis ( $>$ Fig. 1). Diagnostic ultrasound imaging is performed exclusively by radiology in only $4(1.7 \%)$ of the participating clinics.

The majority of the radiology departments participating in the questionnaire (62\%) use $1-2$ ultrasound units. Over half of these departments (52.3\%) have mid-range units, $36.3 \%$ use high-end units and $25.3 \%$ use basic units. Most of the units currently in use are less than 10 years old. Siemens (Siemens Healthcare,
Erlangen, Germany) is the most prevalent ultrasound unit manufacturer in radiology departments within the recorded time frame (year of manufacture "prior to 2000" to 2015, divided into 5 time periods). Other important manufacturers of ultrasound systems used in radiology departments in Germany in recent years are listed in descending order: General Electric (GE Healthcare, Boston, USA), Philips (Philips Healthcare, Amsterdam, the Netherlands) and Toshiba (Toshiba Medical, Tokyo, Japan). The order of Philips and Toshiba was reversed only in the case of older units manufactured prior to 2005.

$69.6 \%$ of the radiology departments performing ultrasound use an electronic documentation system for ultrasound diagnosis. $82.3 \%$ of clinics have a PACS connection for ultrasound regardless of whether ultrasound is performed by radiology or another department. In addition to individual images, video sequences (71.3\%) can usually also be recorded.

\section{Contrast-enhanced ultrasound (CEUS) and interdisciplinarity}

In total, contrast-enhanced ultrasound is performed only by $26.6 \%(n=63)$ of all of the radiology departments that participated in the questionnaire. Even in the group of radiology departments performing ultrasound in general, only $32.6 \%$ use CEUS. It is striking that CEUS is used much more frequently in large radiology departments than in medium-sized departments and particularly in small departments. $65.1 \%$ of radiology users perform $<5$ CEUS examinations per week. $22.2 \%$ of users perform $5-10$ and $11.1 \%$ of users perform $>10$ CEUS examinations per week.

$73 \%$ of informed consent discussions for a CEUS examination in radiology departments are conducted in writing using a standardized informed consent form. In $9.5 \%$ of cases, the primarily verbal informed consent discussion is documented in the written report and in $15.9 \%$ of cases only a verbal informed consent discussion is performed. 


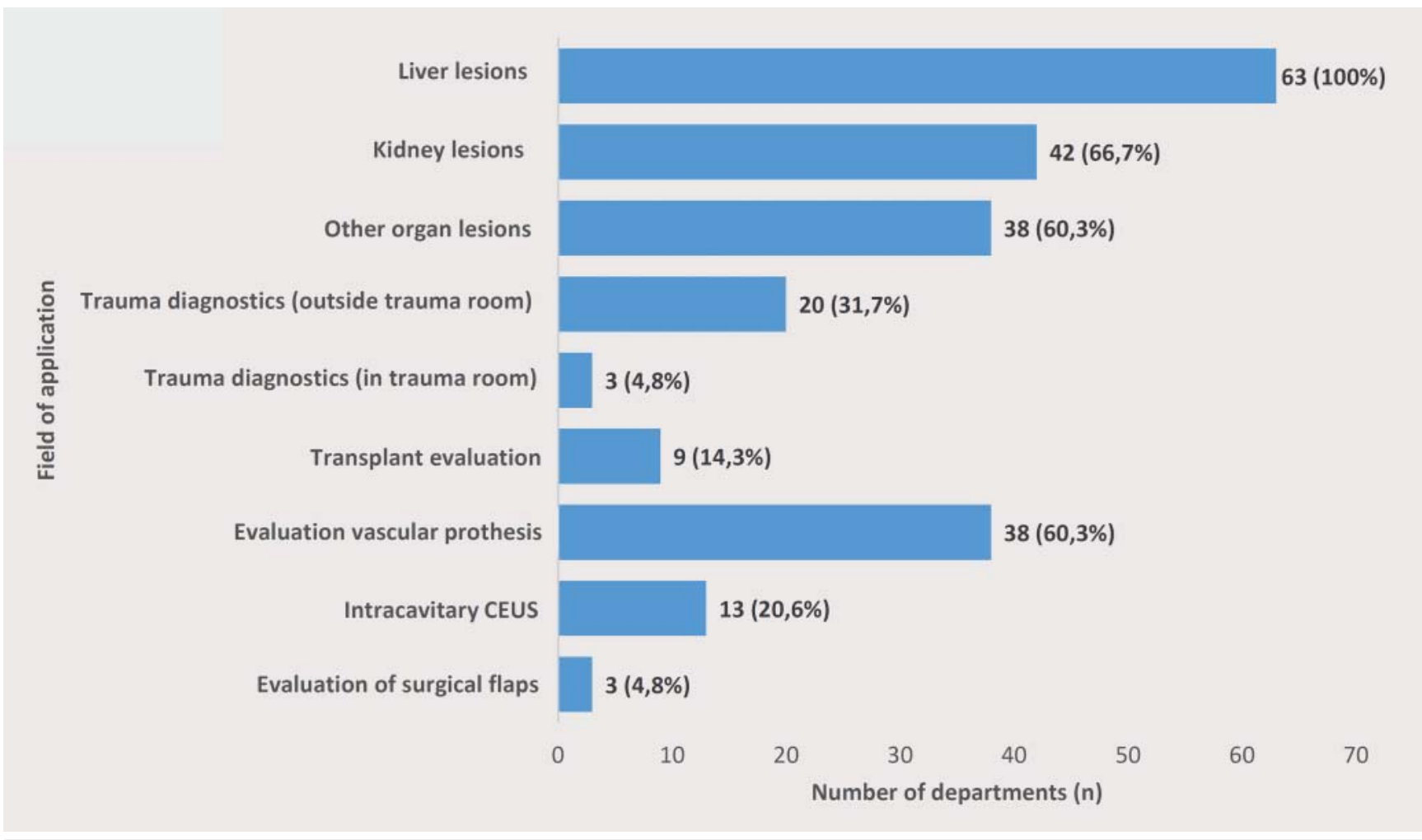

- Fig. 2 Fields of application for CEUS within radiology departments performing CEUS.

The fields of application for CEUS in radiology are broad. $100 \%$ of the radiology departments already using CEUS use the method to assess liver lesions, while $66.7 \%$ use it to evaluate kidney lesions, $60.3 \%$ to assess other organ lesions, and $60.3 \%$ to follow-up vascular prostheses ( $\triangleright$ Fig. 2 ). CEUS is used relatively rarely for diagnosis in trauma cases outside of the trauma room (only $31.7 \%$ of the departments) and is used even more rarely in the trauma room ( $4.8 \%$ of the departments). However, radiologists already using CEUS in different areas see significant potential to increase application of the method by $20.6 \%$ in kidney lesions, by $20.6 \%$ in other organ lesions, by $14.3 \%$ in the diagnosis of trauma cases outside the trauma room, by $22.2 \%$ for diagnosis in the trauma room, by $7.9 \%$ for transplant evaluation, by $23.8 \%$ for the follow-up of vascular prostheses, by $17.5 \%$ for intracavitary CEUS, and by $20.6 \%$ in the evaluation of surgical flaps. Even radiology departments not currently performing CEUS (73.4\%; $n=174$ ) see a broad spectrum of potential indications for this modality. In total, $59.2 \%(n=103)$ of CEUS non-users responded to the question regarding their own potential areas of application. The weighting of these possible areas of application is similar to that of CEUS users. Therefore, liver lesions are at the top of the list of potential indications ( $91.3 \%$ of CEUS non-users) followed by the evaluation of kidney lesions (64.1\%), other organ lesions (56.3\%) and the follow-up of vascular prostheses (50.5\%). All other potential indications were specified by fewer than $20 \%$ of CEUS non-users (not separately shown). - Fig. 3 shows areas of application among CEUS users in radiology, possible additional new application areas among CEUS users, and possible areas of application of the method among non-users. This figure shows the significant potential for increasing the use of this method in radiology departments in absolute numbers. If the radiologists currently using CEUS $(n=63)$ and non-users who see possible areas of application in their departments $(n=103)$ are combined (no data regarding potential areas of application for CEUS from 71 non-users), $70 \%$ of all respondents $(n=237)$ see high potential for the inclusion of CEUS in radiology.

CEUS examinations are currently usually performed in internal medicine, in gastroenterology departments in particular. In principle, the method is widely used in clinics by $88.2 \%$ of internal medicine departments. Only $10.1 \%$ of surgical departments use the method ( $\vee$ Fig. 4 ).

In $46 \%$ of cases, CEUS findings are discussed in interdisciplinary meetings with participation of radiology - even if the method was not performed by radiology. $87.8 \%(n=208)$ of the departments that responded to the questionnaire do not have an interdisciplinary ultrasound department with involvement of radiology. Most of the $12.2 \%$ of departments with an interdisciplinary ultrasound department are run together with internal medicine ( $>$ Fig.5). Of the 29 radiology departments with an interdisciplinary ultrasound department, CEUS is performed by radiologists in $55.2 \%$ of cases. If CEUS is not performed by radiologists in this group, it is performed by other disciplines involved in the ultrasound department in an additional $34.5 \%$ of cases. Thus, there is broad direct access to this method for radiologists within such a department or by creating such a department (89.7\%). Interest in operating an interdisciplinary ultrasound department with involvement of radiology is very high at $64.4 \%$, which is in stark contrast to the currently low number of such facilities. $81.1 \%$ of respon- 

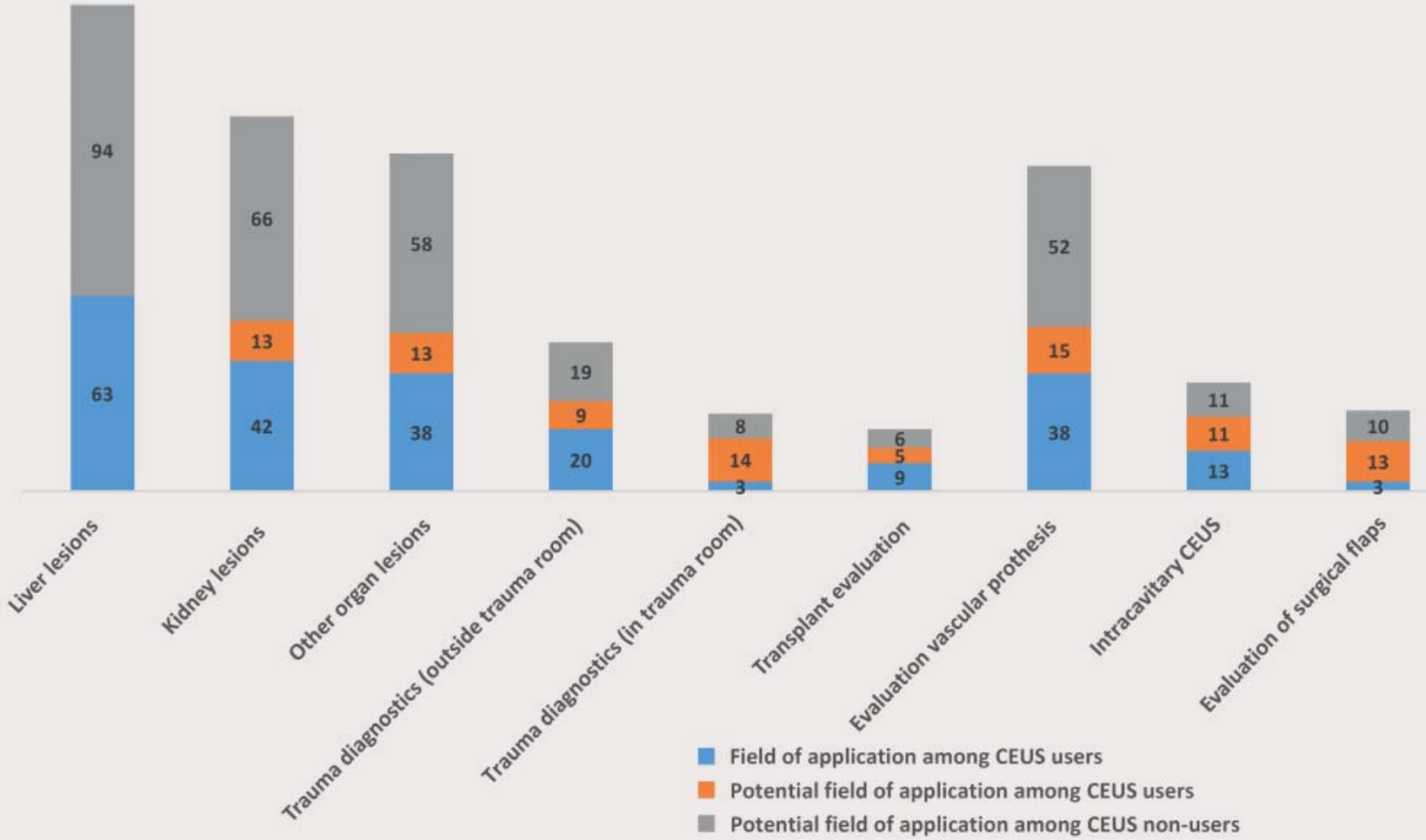

- Fig. 3 Overview of the fields of application for CEUS in radiology (absolute numbers): Existing fields of application for CEUS, potential additional new fields of application for CEUS users and potential fields of application for previous non-users.
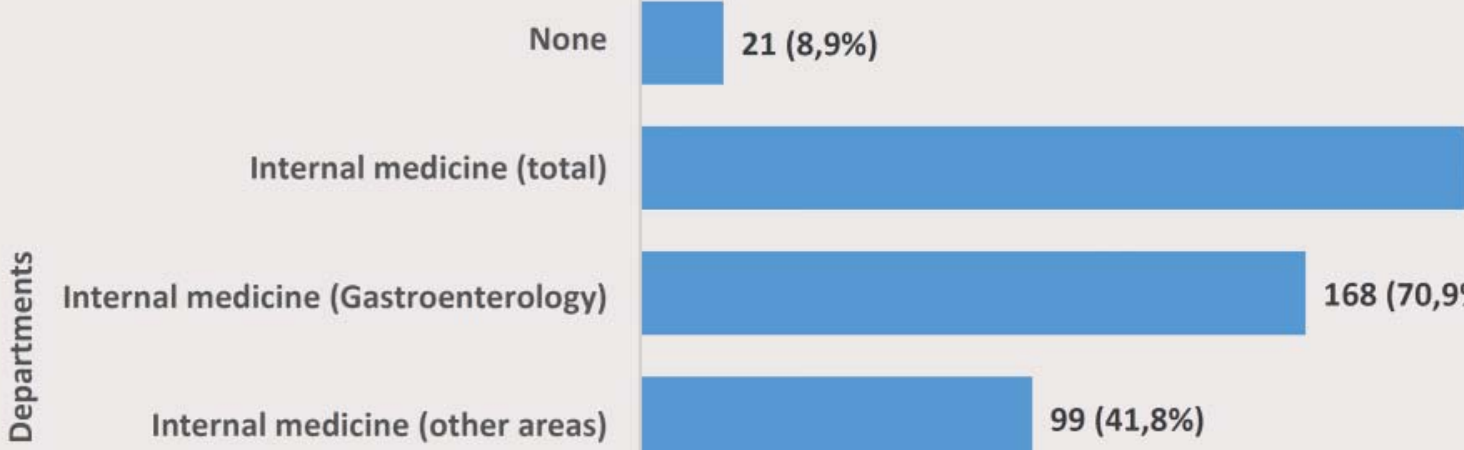

$209(88,2 \%)$

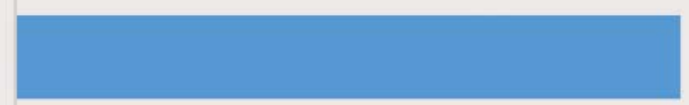

$168(70,9 \%)$

Surgery

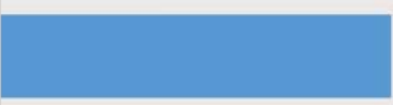

$99(41,8 \%)$

Others

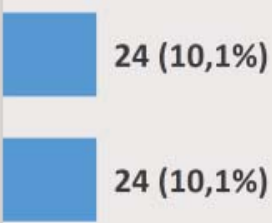

0

50

100

150

Number of departments ( $n$ )

- Fig. 4 Medical disciplines performing CEUS (apart from radiology). 


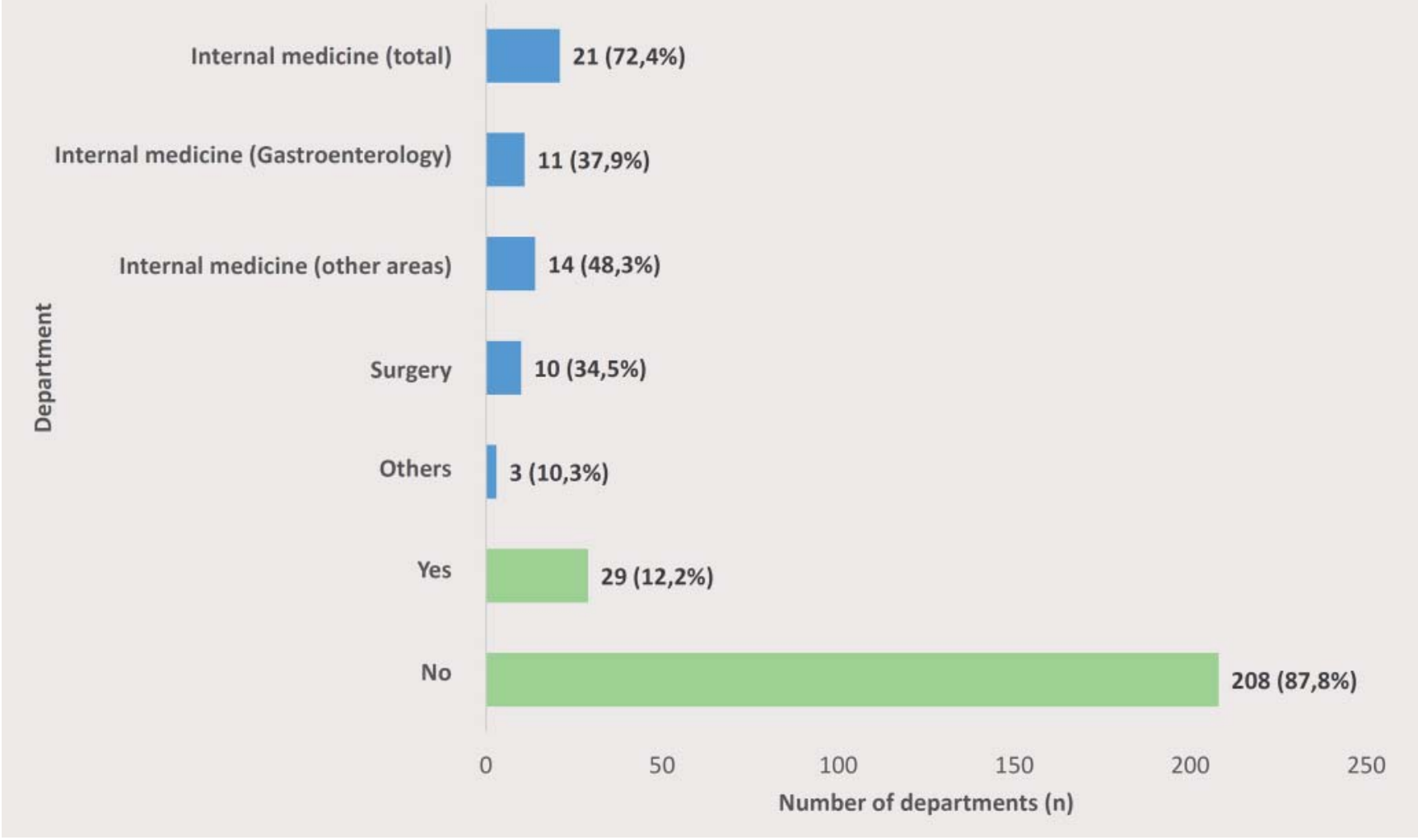

- Fig. 5 Existence of an interdisciplinary ultrasound department with the involvement of radiology "yes/no". If "yes", the cooperating disciplines are marked in blue.

dents were in favor of interdisciplinary collaboration with colleagues in internal medicine ( $\triangleright$ Fig. 6).

\section{CEUS in pediatric radiology}

Only $11.8 \%(n=28)$ of respondents also perform CEUS in children and adolescents. This corresponds to $44.4 \%$ of the group of radiologists performing CEUS. Patients of all age groups ( 0 to $<1=5$ years; $>5$ to $</=10$ years; $>10$ to $</=14$ years; $>14$ years) are examined with CEUS.

Also in the pediatric population, CEUS is primarily used in the diagnosis of liver lesions (performed by $78.6 \%$ of the departments) as well as in other organ lesions (performed by $67.9 \%$ of the departments). Contrast-enhanced voiding urosonography still has a moderately high value in pediatric radiology (performed by $42.9 \%$ of the departments). However, with respect to diagnosis in trauma cases outside the trauma room (39.3\%) and diagnosis in the trauma room (10.7\%), CEUS has a low value in pediatric radiology and only a slightly higher value compared to radiology in adults ( $\triangleright$ Fig. 7). The majority of departments performing CEUS in pediatric radiology state that in addition to the informed consent discussion (following one of the already specified procedures), parents are informed of the current off-label situation for use in children in Germany (67.9\%).

\section{Education/professional development}

Ultrasound education within radiology departments is structured as "learning by doing" in $21.9 \%$ of cases, on the basis of courses in $56.1 \%$ of cases, and using a supervision system in $73 \%$ of cases (multiple responses were possible).

$54.9 \%$ and thus more than half of all respondents would welcome the inclusion of CEUS in the requirements catalog for the specialist examination in radiology. $74.6 \%$ of CEUS users would approve the integration of CEUS in the requirements catalog for the specialist examination in radiology, while $47.7 \%$ of current CEUS non-users (with 6 abstentions from voting) would also support such an inclusion ( $\triangleright$ Fig. 8 ). With respect to the possible inclusion of CEUS in the requirements catalog for the specialist examination, $19.4 \%$ of respondents are in favor of proof of competency, for example, on the basis of a 3-day required course (knowledge, technique, indication, possibilities of CEUS, etc.). $11 \%$ of respondents could imagine proof of competency on the basis of the number CEUS examinations performed. With $61.2 \%$, the majority of respondents would prefer a flexible system: Using one of the defined options depending on local availability and currently available training in this technique.

With a rate of $62.4 \%$, approximately $2 / 3$ of all respondents are interested in professional development in CEUS. $82.9 \%$ of large radiology departments with more than 20 physicians are highly interested followed by medium-sized departments (69\%) and smaller departments with fewer than 10 physicians (55.1\%). 
Yes, with Internal medicine (total)

Yes, with Internal medicine (Gastroenterology)

Yes, with Internal medicine (other areas)

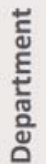

Yes, with Surgery

Yes, with another department

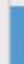

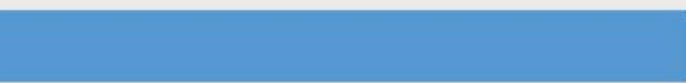

$118(88,1 \%)$
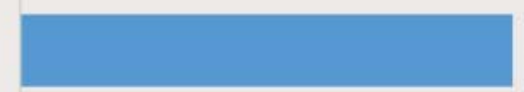

$83(61,9 \%)$

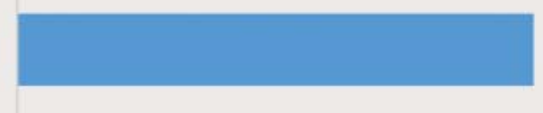

$87(64,9 \%)$

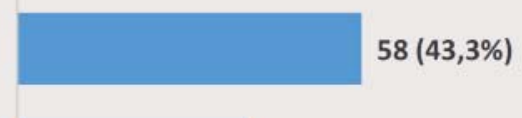

$39(29,1 \%)$

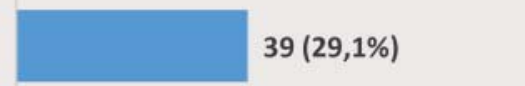

Yes

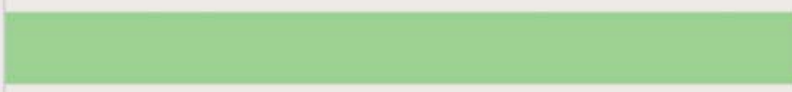

$134(64,4 \%)$

No

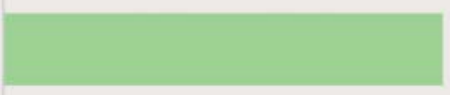

$74(35,6 \%)$

$0 \quad 20$

40

60

80

100

120

140

160

- Fig. 6 Clinics without an interdisciplinary ultrasound department with the involvement of radiology. Such a department would be desirable "yes/ no". If "yes", the preferred cooperating disciplines are marked in blue.

\section{Outlook}

$48.9 \%$ of the participating departments are familiar with fusion imaging, i.e., US/CEUS with (PET) CT/MRI. $63.7 \%$ of respondents feel that the development of ultrasound-coupled fusion imaging brings ultrasound closer to radiology.

$78.5 \%$ of respondents feel that better compensation could help to further establish CEUS in radiology.

On a scale of 1 (low) to 7 (high), the future value of CEUS is rated as medium to high ( $\nabla$ Fig. 9). This applies both to CEUS users and non-users. The value is rated higher among CEUS users than non-users ( $\triangleright$ Fig. 10).

\section{Discussion}

The nationwide questionnaire study to determine the value of CEUS in radiology had a very high response rate of $42.3 \%$. This reflects the recognition of the value of CEUS by radiology.

However, only a few radiologists use CEUS regularly. The high diagnostic value of CEUS has been shown for years by various medical disciplines [1-7, 9]. In general, it can be assumed that the majority of the $57.7 \%$ of departments that did not respond to the questionnaire do not perform CEUS and possibly not even US and therefore have less interest in the topic than the respondents. Therefore, the actual percentage of radiologists preforming CEUS is probably even significantly lower than the value of $26.6 \%$ presented in the study. Under this assumption, a correspondingly lower percentage of radiology departments performing ultrasound in general would also be expected than shown by the study results of $81.4 \%$ in total and $78.5 \%$ in routine diagnostic imaging.

The study also shows that US and in particular CEUS as an important imaging modality according to current perception is primarily used in internal medicine with a focus in gastroenterology [12]. The number of ultrasound units in radiology departments is usually small but in most cases the systems are modern and have a high device class resulting in significant technical potential that would allow more comprehensive use of CEUS. In addition, $82.3 \%$ of clinics already have a PACS connection for ultrasound, usually with the option of archiving video sequences. This satisfies an important requirement for better integration of the method in radiology.

CEUS users in radiology who are currently usually at larger clinics as well as non-users in particular feel that there are comprehensive additional and new applications for the method in their departments. This indicates significant potential for an increase in the use of CEUS. The fact that this potential for increased use is also recognized by CEUS users is reflected by their often low examination numbers. The study was able to show that CEUS technology has a high value for radiology users for the diagnosis of organ lesions - primarily the liver - and also for diagnosing endoleaks in the follow-up of vascular prostheses. However, in light of the fact that CEUS is highly useful for the diagnosis of trauma cases [7], it is interesting that the method has been used to date only relatively rarely for this purpose outside the trauma room and extremely rarely in the trauma room.

To date, CEUS findings tend to be discussed on a suboptimal basis in interdisciplinary meetings with participation of radiology. Moreover, interdisciplinary ultrasound departments with involve- 


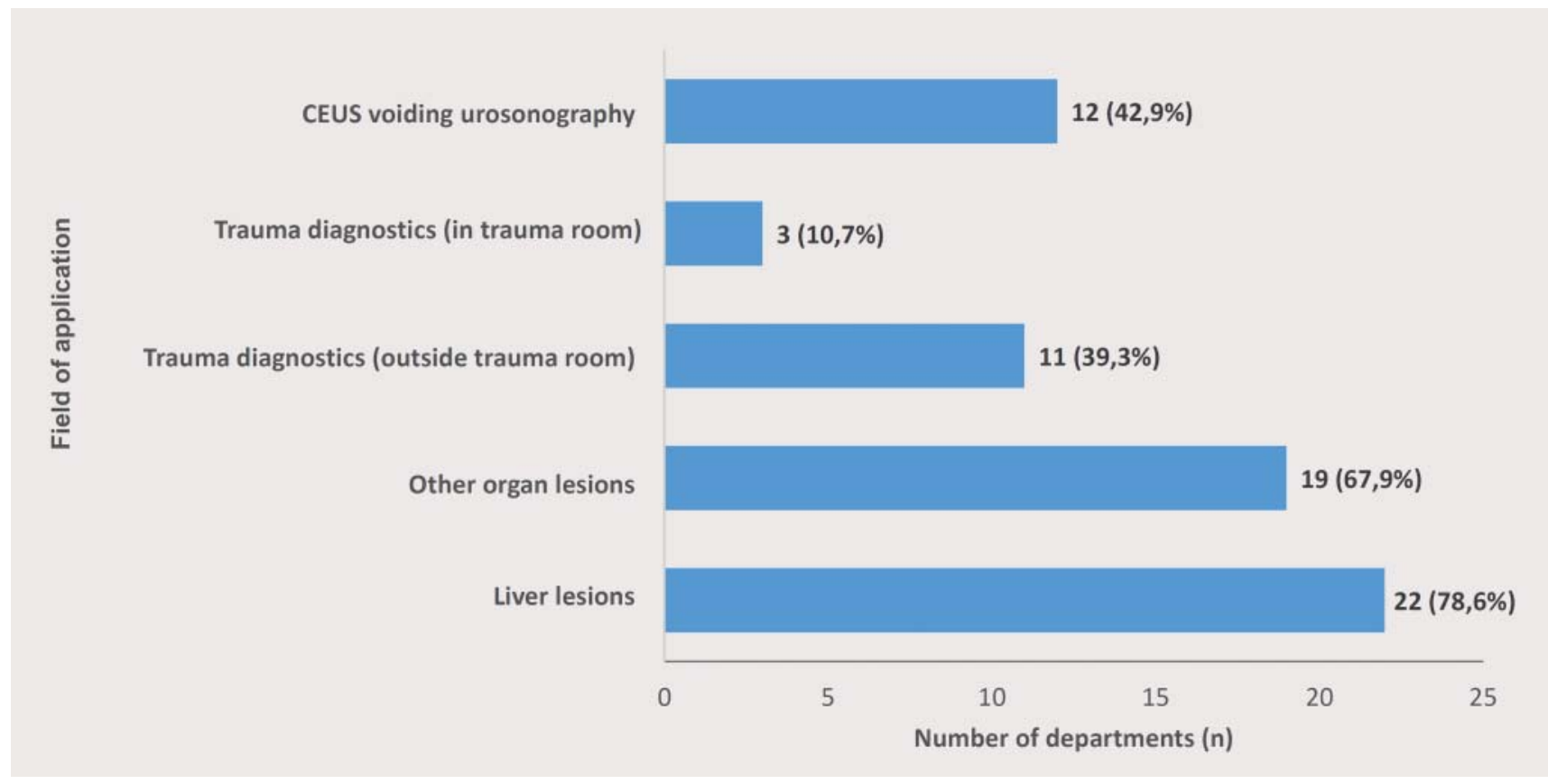

- Fig. 7 Fields of application for CEUS within the 28 departments, performing CEUS in pediatric radiology.

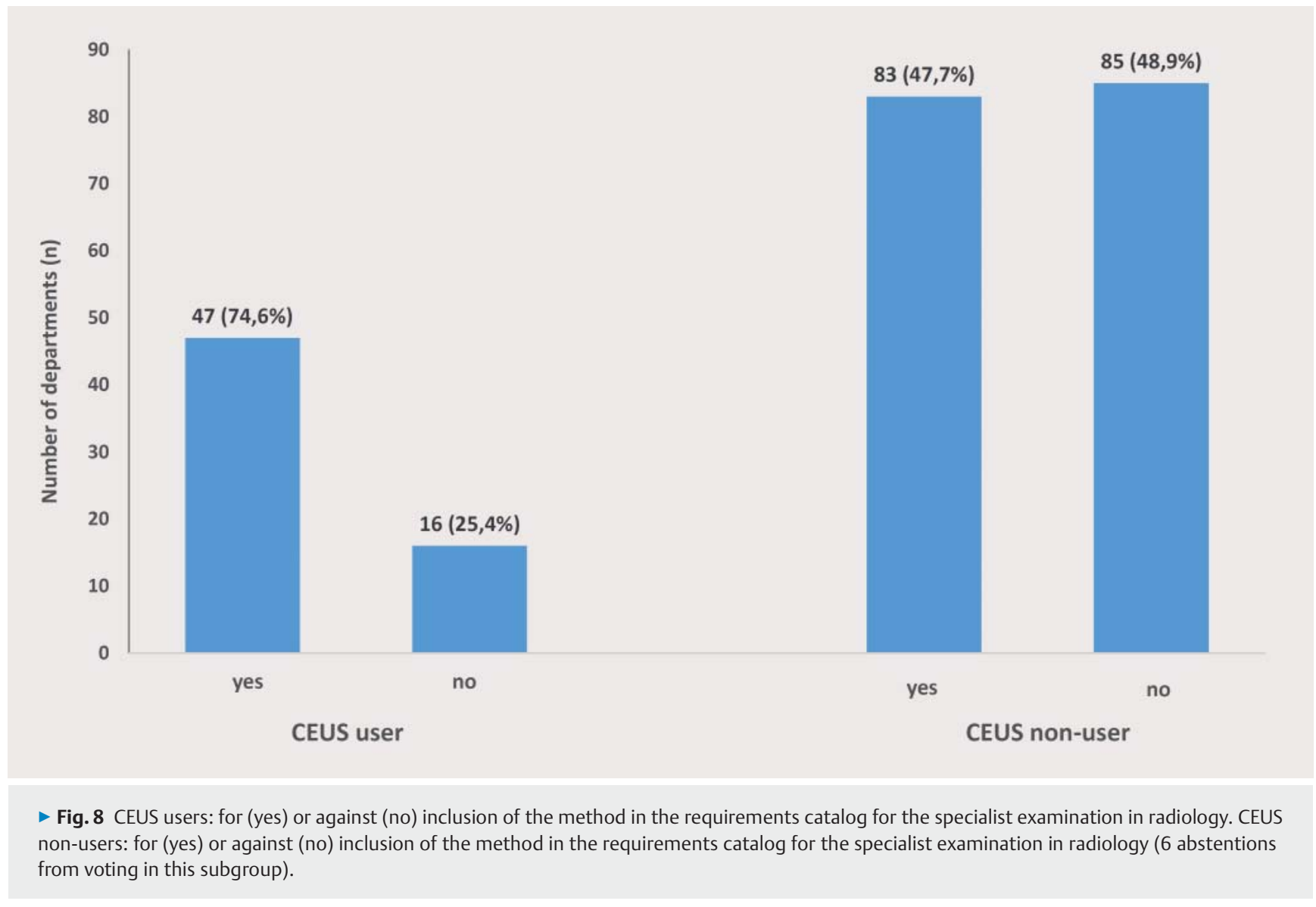




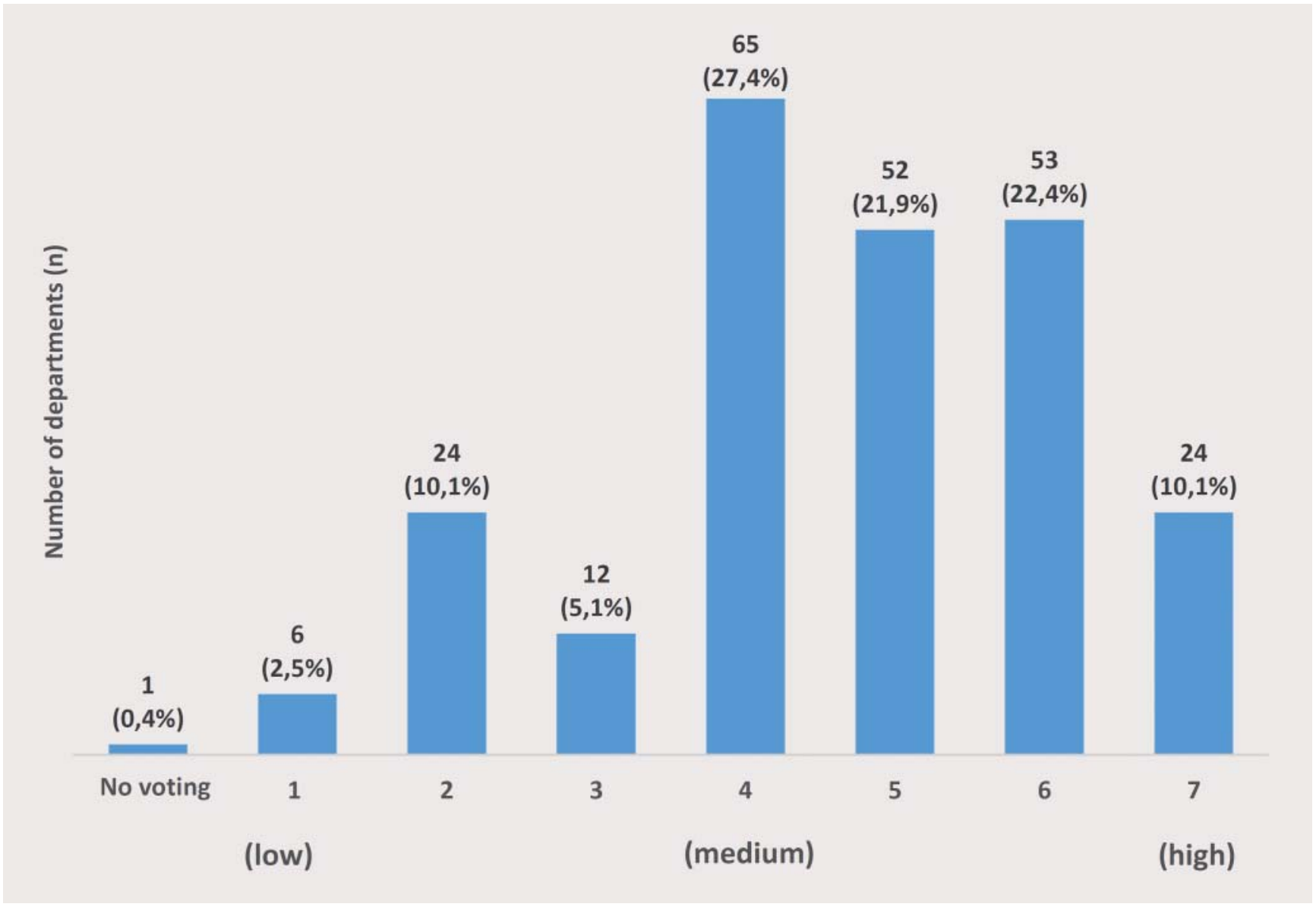

- Fig. 9 Future importance of CEUS as seen by radiologists: $1=$ lowest importance, $7=$ highest importance.

ment of radiology are still quite rare (12.2\%). However, the interest in operating an interdisciplinary ultrasound department with involvement of radiology is very high at $64.4 \%$. Existing interdisciplinary ultrasound departments are usually run together with internal medicine. Even when establishing a new ultrasound department, cooperation with internal medicine is preferred. The analysis also shows that radiologists in established interdisciplinary ultrasound departments perform CEUS at a much higher rate than when there is no such department. Even if CEUS is not used by the radiologists within the department, it is usually performed by another discipline involved in the ultrasound department so that radiologists still have direct access to the method. Thus, the formation of interdisciplinary ultrasound departments promotes the use of CEUS (89.7\%) and can thus help to expand the education options for radiologists in this modality [13].

Although CEUS is an extremely gentle method, it is underrepresented even in pediatric radiology, possibly as a result of the current "off-label" situation in this country. However, parents are informed of this situation during the informed consent discussion in the majority of cases. The FDA recently approved CEUS for diagnostic liver imaging in children in the USA [10]. Approval of CEUS in pediatric diagnostic imaging can also be expected in Europe. Continued underrepresentation of CEUS in pediatric radiology would constitute a major missed opportunity to reduce the use of less gentle imaging modalities.

While CEUS for the evaluation of organ lesions and in particular liver lesions currently has high value in pediatric radiology, voiding urosonography as a radiation-free alternative to conventional radiology methods in the region of the gonads is used significantly more rarely by CEUS users in pediatric radiology. The low representation of CEUS in diagnosis in trauma cases outside and especially in the trauma room in pediatric radiology is particularly striking. Amazingly, the percentage of use of this radiation-free modality with no systemic contrast toxicity and the ability to visualize organ lacerations with high sensitivity in the latter indications is only insignificantly higher than in radiology in adults [7].

In radiology departments, ultrasound education is largely standardized on the basis of courses teaching the basic principles and in particular as a result of supervision in the clinical routine and is thus usually well structured. There is high to very high interest in radiology in professional development courses in CEUS.

The primarily supportive view of the integration of CEUS in the requirements catalog for the specialist examination in radiology is positive. Not only those already performing CEUS but also those currently not using the method are open to such a development and support a flexible solution for providing proof of competency either based on the number of CEUS examinations per- 


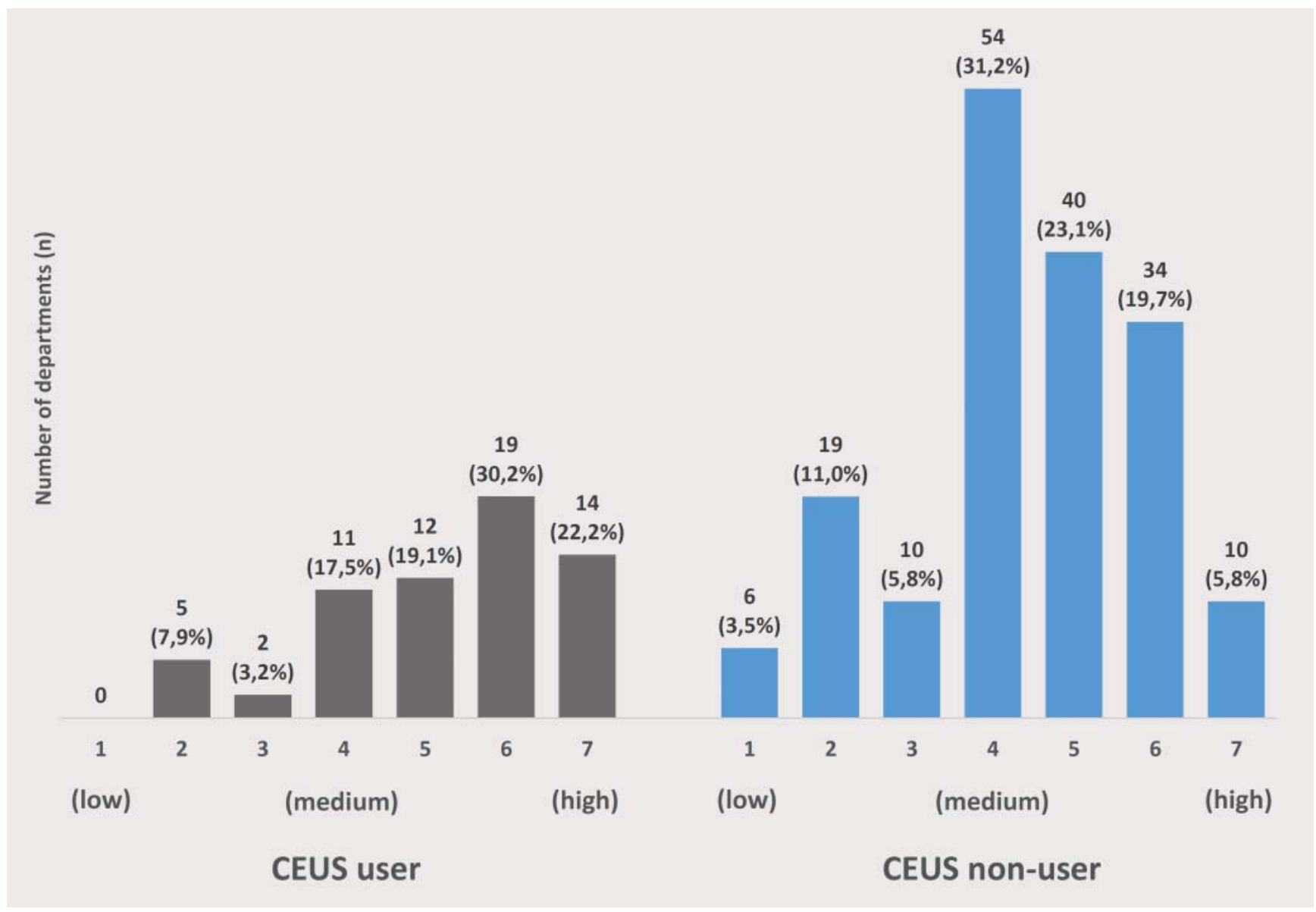

- Fig. 10 Future importance of CEUS as seen by radiologists, differentiated by CEUS users and CEUS non-users: $1=$ lowest importance, $7=$ highest importance.

formed or on the basis of a mandatory CEUS course depending on local availability and current education options in this technique. Inclusion of CEUS in the requirements catalog for the specialist examination would certainly be a decisive step toward better integration of US and in particular CEUS in radiology. The consequently greater direct connection to clinically oriented diagnostic ultrasound imaging is important and would open up new options for radiology. If ultrasound is viewed in the future also by radiologists as a bedside examination allowing simultaneous recording of the patient's medical history, performing of a physical examination, and imaging and if the potential resulting from the further technical developments of ultrasound and CEUS is recognized, it is conceivable that radiology will become a closer clinical partner for other disciplines in this area. In particular, the clinical position of radiology in the increasing overlap of various discipline-specific diagnostic methods must always be expanded and its value must not be neglected. Moreover, the spectrum of added diagnostic value due to the ability to perform multimodal assessment of pathologies as presented to radiologists by combining US/CEUS and $C T / M R I$ is extremely valuable for radiology.

However, discussions about introducing non-physician sonographers in ultrasound in radiology, a field that will initially require further development and will become increasingly complex, should be viewed critically with respect to the desired quality of education in the method and the preferred level of importance of the method. In addition, the desired acceptance of radiological services by physicians in clinical practice and the important definition of the irreplaceable medical services provided by our discipline would be greatly weakened by the introduction of non-physician sonographers.

Almost half of radiologists are familiar with the possibilities of fusing US/CEUS with CT/MRI and approximately 2/3 are the opinion that this technical development should bring ultrasound closer to radiology [14-16]. $78.5 \%$ of respondents admitted that economic considerations affect medical decisions as in many areas of medicine in that they share the opinion that better compensation for CEUS could help to promote further establishment of the method in radiology.

The responses to the final scaled question show that the future value of CEUS tends to be rated as high. The fact that this is true not only for CEUS users but also for current non-users shows the high appreciation that many radiologists have for this method.

\section{Conclusion}

The high response rate of the nationwide questionnaire study regarding the value of CEUS in radiology reflects the recognition of 
the importance of the topic by the radiology community. There was a major discrepancy between the currently low application of the method in radiology and the high ranking of CEUS by many radiologists. There is major interest in the modality and significant potential for an increase in the use of the method in radiology is seen. This analysis is intended to prompt important discussions in professional policy within the radiology community.

\section{CLINICAL RELEVANCE OF THE STUDY}

- Despite the fact that contrast-enhanced ultrasound (CEUS) has been established for years and has high diagnostic value, it is used only rarely by radiologists and is primarily performed by other medical disciplines.

- There was a major discrepancy between the currently low application of CEUS in radiology and the high ranking of CEUS by many radiologists.

- The analyses of the replies point out important aspects of professional policy regarding this topic within the radiology community.

\section{Conflict of Interest}

The authors declare that they have no conflict of interest.

\section{References}

[1] Claudon M, Dietrich CF, Choi BI et al. Guidelines and good clinical practice recommendations for the Contrast Enhanced Ultrasound (CEUS) in the liver- update 2012: a WFUMB-EFSUMB initiative in cooperation with representatives of AFSUMB, AIUM, ASUM, FLAUS and ICUS. Ultraschall in Med 2013; 34: 11-29

[2] Hohmann J, Skrok J, Puls R et al. Charakterisierung fokaler Leberläsionen mit kontrastmittelgestütztem „low MI real time“ Ultraschall und SonoVue. Fortschr Röntgenstr 2003; 175: 835-843

[3] Quaia E, Calliada F, Bertolotto M et al. Characterization of focal liver lesions with contrast-specific US modes and a sulfur hexafluoride filled microbubble contrast agent: diagnostic performance and confidence. Radiology 2004; 232: 420-430

[4] Clevert DA, Schick K, Chen MH et al. Role of contrast enhanced ultrasound in detection of abdominal aortic abnormalities in comparison with multislice computed tomography. Chinese Medical Journal 2009; 122: $858-864$

[5] Clevert DA, Minaifar N, Kopp R et al. Imaging of endoleaks after endovascular aneurysm repair (EVAR) with contrast-enhanced ultrasound (CEUS). A pictorial comparison with CTA. Clin Hemorheol Microcirc 2009; 41: $151-168$

[6] Piscaglia F, Nolsae C, Dietrich CF et al. The EFSUMB Guidelines and recommendations on the clinical practice of Contrast Enhanced Ultrasound (CEUS): update 2011 on non-hepatic applications. Ultraschall in Med 2012; 33: 33-59

[7] Sessa B, Trinci M, lannello $S$ et al. Blunt abdominal trauma: role of contrast-enhanced ultrasound (CEUS) in detection and staging of abdominal traumatic lesions compared to US and CE-MDCT. Radiol Med 2015; 120 : $180-189$

[8] Albrecht T. Kontrastmittelgestützter Ultraschall der Leber - Herausforderung und Chance für die deutsche Radiologie. Fortschr Röntgenstr 2003; 175: 889-891

[9] S3- Leitlinie hepatozelluläres Karzinom - DGVS, Mai 2013.

[10] Seitz K, Strobel D. A milestone: Approval of CEUS for diagnostic liver imaging in adults and children in the USA. Ultraschall in Med 2016; 37 : 229-232

[11] Schlief R, Bauer A. Ultraschallkontrastmittel. Neue Perspektiven in der Ultraschalldiagnostik. Radiologe 1996; 36: $51-57$

[12] Bleck JS. Basic principles of ultrasonography and its relevance for internal medicine. Der Internist 2012; 53: 251 - 260

[13] Wüstner M, Mertiny E, Busch HP. Arbeitsweise eines interdisziplinären Ultraschallzentrums. Klinikarzt 2012; 41: 47-51

[14] Jung EM, Clevert DA. Möglichkeiten der sonographischen Fusionsbildgebung. Der Radiologe 2015; 55: 937 - 948

[15] Lee MW. Fusion imaging of real-time ultrasonography with CT or MRI for hepatic intervention. Ultrasonography 2014; 33: 227-239

[16] Rennert J, Georgieva M, Schreyer AG et al. Image fusion of contrast enhanced ultrasound (CEUS) with computed tomography (CT) or magnetic resonance imaging (MRI) using volume navigation for detection, characterization and planning of therapeutic interventions of liver tumors. Clini Hemorheol Microcirc 2011; 49: 67-81 
